\begin{tabular}{|c|c|}
\hline Title & $\begin{array}{l}\text { Understanding Nature through Photography : A n Empirical A nalysis of the Intents of Nature Photographers and the } \\
\text { Preparatory Process }\end{array}$ \\
\hline Author(s) & Ohara, Naoyuki; Y amanaka, Y asuhiro; Trencher, Gregory \\
\hline Citation & $\begin{array}{l}\text { Environmental communication, 13(8), 1053-1068 } \\
\text { https://doi.org/10.1080/17524032.2019.1572638 }\end{array}$ \\
\hline Issue Date & $2020-06-23$ \\
\hline Doc URL & http:/hdl.handle.net/2115/78658 \\
\hline Rights & $\begin{array}{l}\text { This is an A ccepted Manuscript of an article published by Taylor \& Francis in Environmental communication on } 20 \text { Jun } \\
\text { 2019, available online: https://www.tandfonline.com/doi/abs/10.1080/17524032.2019.1572638 }\end{array}$ \\
\hline Type & article (author version) \\
\hline File Information & FInal manuscript for EC (Ohara_Y amanaka Trencher) .pdf \\
\hline
\end{tabular}

Instructions for use 


\title{
Understanding nature through photography: An empirical analysis of the intents of nature photographers and the preparatory process
}

\author{
Naoyuki Ohara ${ }^{1}$, Yasuhiro Yamanaka ${ }^{2}$, and Gregory Trencher ${ }^{3}$. \\ 1. Graduate School of Environmental Science, Hokkaido University, Hokkaido, Japan \\ 2. Faculty of Environmental Earth Science, Hokkaido University, Hokkaido, Japan \\ 3. Graduate School of Environmental Studies, Tohoku University, Miyagi, Japan
}

\begin{abstract}
This study examined the intent, preparatory processes and challenges of nature photographers mainly shooting plants and animals in northern Japan. Findings revealed efforts to actively absorb scientific knowledge related to subjects during the preparatory process. Thus, a core intention is to capture nature in a scientifically credible manner, thereby demonstrating intimate understanding of subjects acquired from both scientific knowledge and first-hand field observations. In constructing their self-identity and attributing purpose to their work, photographers are grappling with internal tensions and contradictions when deciding the optimal distance to place between their field and related professions such as stock photography and artistic expression. We also observed cases where the original intentions of scientifically credible images from nature photographers might be lost as images are freely diffused via digital stock photo libraries. This harbors implications for the ability of the public to knowingly view photographs with a sort of “quality assurance” based on natural science.
\end{abstract}

\section{Keywords}

Nature photography; nature photographer; environmental advocacy; stock photography

\section{Introduction}

Nature photography has largely contributed to increased understanding into 
natural phenomena and habitats that we are unable to directly observe with the naked eye. Photographs of nature are frequently featured in the public realm in the form of printed communication materials and the websites of environmental protection groups, NGOs and public administrations, and are often exploited to advocate for the preservation and protection of endangered species and the natural environment (Seppannen \& Esa, 2003). In the present day, professionals working in the environmental field often use images of the natural world such as photographs to strengthen the appeal of the particular species and habitats they wish to protect and to rouse public support for conservation (Cox \& Steve, 2015; Deluca, 1997; Doyle, 2007; Foale \& Martha, 2005). Images of polar bears on melting sea ice, which have become a symbol of the global fight against climate change, are a fine example (Tollmann, 2014). Nature photographs are widely used for such purposes in Japan too. For instance, in its National Biodiversity Strategy for 2010, the Japanese Ministry of the Environment included nature photographs taken by famous domestic photographers in the official pamphlet (Ministry of the Environment, 2010).

Previous studies demonstrate that in the past some nature photographers have contributed greatly to the introduction of environmental policies through the legacy of their images (Pezzullo \& Cox, 2018). Although few in number, some nature photographers crusade actively for environmental protection from the outset of the photographic process, much in the spirit of a press photographer. Robert Glenn Ketchum is renowned for succeeding in changing forest conservation policy for Alaska's Tongass rainforest in the late 1980s. Notably, he planned his photographs from the out- set with the intent of triggering a drastic review of domestic forest policy. At the time of publication, he formulated an elaborate political strategy in advance by writing for support to influential people such as activists and scientists who backed the conservation of the region photographed. When Ketchum's photographic book The Tongass: Alaska's Vanishing Rain Forest was published in 1987, he claimed that the Reagan administration had neglected environment conservation and instead prioritized the economic interests of large companies such as the timber and oil industry. In the book's final chapter "Last Stand," he claimed "the fate of Tongass is now in the hands of Congress" and attempted to spread support for conserving the region by urging readers to "inform yourself and let your representative know your position” (Ketchum \& Carey, 1994, p. 109). His efforts were noticed in the United States, and the Tongass Timber Reform Act was enacted in 1990. This law aimed to ensure the expansion of designated wilderness and protected 
areas and establish reductions to permitted timber harvesting quotas. The following year, Ketchum received the Global 500 Roll of Honor from the United Nations Environmental Program that recognizes people deeply involved in solving environmental problems.

While this example demonstrates how the political intentions of a nature photographer succeeded in stirring public support for environmental policy action, there are also cases where photographs have triggered societal changes despite the absence of such explicit intents on the part of the photographer. A photographic exhibition at the Smithsonian Museum in Washington D.C. by Shabhanker Banerjee in 2003 provides an illustrative example. Also documenting the Alaskan region, this exhibition became a big topic among politicians and environmental activists. When planning the shoot, although Banerjee was strongly moved by the beauty of the Alaskan wilderness and aspired to see nature there remain untrammeled by tourism and industry, he never set out intentionally to draw attention to any particular industrial activity in the region. Rather, as the author stated, his photographic intention was more explained by "I was stunned by the biodiversity of the refuge and how little had been documented photographically" (Banerjee, 2003, p. 17). Although this was not the photographer's intent, eventually oil drilling at the shooting location was canceled. The Smithsonian Museum subsequently deemed that his work was too strong in terms of political messages and, after issuing a notice to Banerjee, changed and shrank the contents of his solo exhibition (Egan, 2003). In both these cases, whilst the photographic works and exhibitions from Ketchum and Banerjee both triggered a shift in societal awareness and a dramatic shift in conservation policy, a major distinction between the two lies in the degree of explicit political intention that motivated the works from the outset.

These above examples demonstrate an immense potential in photographic images of the natural world to influence policy and public attitudes towards nature. Yet they also point to the importance of understanding the intentions that compel nature photographers to take certain images. Some previous studies have tackled this topic by inferring the intentions of nature photographs used for environmental purposes by analyzing documents and historical information (Deluca \& Demo, 2000, Nobuoka, 2009). However, real-time empirical research on currently practicing nature photographers based on first-hand and face-to-face accounts has not progressed much. As O’Neil and Nicholas (2014) point out in their review of the types of visual images used by actors such as scientists, politicians, media, and campaigning organizations to communicate various 
dimensions of climate change, there is a need in the literature for ethnographic studies that focus on the intentions driving the moment of production (O’Neil \& Nicholas, 2014). However, scholarship as a whole has so far tended to focus on the societal impacts of particular photographic images rather than the specific intentions of nature photographers and the preparation process taken to help achieve a particular objective. This study thus contributes to the limited literature on this topic by exploring the need to distinguish between the original intent of photographers and subsequent (political) uses of photographs that ignore these motivations. As our research shows, this constitutes a great area of tension for practicing photographers.

In recent years, stock photography has become widespread and images diffused via this medium are widely exploited in society. In addition, as will be brought to light later, this study has found that the rise of stock photos holds important implications for the accurate transmission of the original intentions of nature photographers. In the 1990s, the Japan Professional Photographers Society delivered a highly positive appraisal of the stock photo paradigm, arguing that "Thanks to this mechanism, nature photographers have rapidly gained recognition, one after another" (Japan Professional Photographers Society, 2000, p. 403). However, since the early 2000s, stock photo agencies have undergone significant restructuring, with small companies assimilated by larger competitors, and the remaining firms attaining an enormous scale. Due to the enlargement of this industry, nature photographs are now treated as mere commodities, and the intentions of nature photographers may be less likely to be transmitted.

Against this backdrop, the objective of this study is to build understanding into the specific intentions of nature photographers working in Hokkaido in Northern Japan and the preparatory measures that facilitate this purpose. Specifically, we tackle three research questions: (1) the kind of preparatory measures taken by photographers before shoots and the intent that drives their work, (2) the manner by which these professionals' self-identity and attribute meaning to their role as nature photographers, and (3) challenges encountered in conveying their intent to the public through images, and countermeasures to overcome these. In line with calls from O’Neil and Nicholas (2014) for more empirical studies, we employ qualitative methods that combine data from interview research and document analysis.

Our findings reveal that these photographers invest strenuous efforts to understand their subjects. Overall, a widely shared core intent is to produce images that 
faithfully capture a subject's quintessential behavior and characteristics while also conveying to viewers the photographer's deep understanding of the subject and any new discoveries. This is done by actively acquiring knowledge from the natural sciences and coupling this with intimate understanding gained from extensive first-hand observations in the field. This points to a need to appreciate and respect the intent and educative role played by professional nature photographers in increasing our understanding of the natural world - particularly since society's acquisition of knowledge about nature is increasingly reliant on visual representations from photographers rather than direct experience. In addition, findings show that when constructing their professional selfidentity, nature photographers are wrestling with significant internal tensions and contradiction as they attempt to distinguish their role from that of scientists and artistic or specialized stock photographers. Finally, results also reveal that the increasing circulation of images via digital stock photography libraries is posing significant challenges for the accurate transmission of the true intent of nature photographers, since images can freely be appropriated and used out of context.

\section{Literature review}

From the moment a photograph is taken, intentions are routinely added to the image not only by the photographer but also by editors and subsequent users. As noted by Imahashi (2008), although it is generally believed that photographs are a faithful reproduction of nature cut out from "the decisive moment"- - a name taken from CartierBresson's work-photographs are the result of a conscious selection of images (an act which is itself shaped by biases of the photographer and editors) and the manipulation of gradation, shading and composition before publication. Imahashi also pointed out that the interpretation of photographic images is greatly influenced by their historical, political and cultural backgrounds at the time of publication. Concurring with this point, Sontag (1979) argues that publishers and the media largely dictate the framework within which photographs are produced, and that the general public readily regard photographs as a snippet of the real world.

Existent scholarship examining the intent of nature photographers has mostly tackled this issue by inferring motivations retrospectively from particular images or the wider socio-historical context surrounding their work (e.g. Dunaway, 2005). This literature has produced understanding that although the intent of photographers has been 
occasionally misused or misread by users and critics (Deluca \& Demo, 2000; Nobuoka, 2009), there have been some cases where publishers respected the intent of photographers and reflected them in the publication of their works.

To cite a case of interest, in the late nineteenth century in the urban areas of the United States, photographs of Carlton Watkins were used for the purposes of promoting conservation activities in Yosemite. Deluca and Demo (2000) conducted a visual criticism on the works of Watkins from the viewpoint of subject matter that did not feature in his photographs. As a result of this approach, they discovered that the life and traces of Native Americans and miners-although key inhabitants in Yosemite-were omitted entirely as subject matter in his photographs. This research lead to the conclusion that Watkins himself did not intend to photograph the nature of Yosemite to reflect any political circumstances of the United States. Rather, he viewed and photographed Yosemite's wilderness from a Christian viewpoint as a new world specially created by God. Despite this, Watkin's images were actively used in a political context by the American Government as a means to rebuild the American identity, which had been crushed by the Civil War, and to advertise “a pristine wilderness” to the public. Thus Deluca and Demo’s research revealed a great gap between the religious intention that Watkins tried to photograph and the political intention that was later added by the government agencies publishing their images.

A doctoral dissertation from the field of comparative culture studies on a famous Japanese nature photographer Michio Hoshino (whose lifelong work was dedicated to documenting the wilderness of Alaska until 1995) is one of the few studies of individual nature photographers in Japan (Nobuoka, 2009). Whilst Hoshino's ideas have been fragmentally cited after his fatal accident, Nobuoka's research has played a large role in comprehensively clarifying the ideas he held regarding his work. As Nobuoka analyzed from Hoshino's essay and lectures, Hoshino did not fully support nature conservation and animal welfare. Moreover, he appeared to hold a positive view of modernization. By comparing the words that Mr. Hoshino himself spelled out in his various essays with the texts of those who criticized him, Nobuoka's research revealed that the intentions of Hoshino were greatly distorted by criticism after his death.

Dunaway (2005) pointed out that historical photographers and filmmakers who photographed American wildlife and landscapes have contributed greatly to the environmental conservation movement, and largely shaped public perceptions of the 
environment. In addition, he examined the case of nature photographer Herbert W. Gleason, whose photographs were newly inserted into Henry Thoreau's novel Life in the Woods published by Houghton Mifflin. Dunaway pointed out how Houghton Mifflin took great care to confirm the intent of Gleason's images before publication in order to assess their suitability for his work. As clarified from his lectures, documents and the contents of his photographs, Dunaway revealed that Gleason's intent was to sanctify the existence of Thoreau. The publisher also advertised that Gleason had traveled to "the very spots" described by Thoreau, and called Gleason "an ardent lover of nature” (Mifflin in Dunaway, 2005, p. 15).

A common feature in the literature showcased to this point is that, given that the photographers concerned were no longer alive at the time of study (and therefore unable to be contacted for verification), their intent has been retroactively and indirectly inferred from relevant images, lectures, and texts. Although some research has been able to confirm with practicing photographers about the intent of their photographic activities (Dunaway, 2005), to date there is a lack of literature that seeks to explicitly build empirical understanding about the preparatory stage before shooting. As such, knowledge is visibly lacking into points such as the objectives of nature photographers and preparatory measures taken to this end, the nature of their relationships with other professional communities, their ideas and the self-identity they construct through their work, and challenges faced in adequately conveying their intentions to publishers and viewers. One notable exception however is the empirical work of Schwarz (2013) who has surveyed the practices of contemporary conservation photographers in the United States to build understanding into the political strategies used to arouse public support for nature conservation while, in another study, using interview methods to understand the impact of online publishing platforms on their professional practices (Gervais, 2016). Given that research is limited beyond Schwarz's work, our study tackles our research questions by meeting directly with practicing nature photographers to gain first-hand insights into their experiences. This overcomes the limitation of previous research, which has tended to mostly target famous, deceased photographers who were able to extensively publish their works and actively communicate their opinions. Thus, in addition to seasoned veterans, in this study we included nature photographers who are yet to widely publish their work or publicize their opinions. Do such nature photographers yet to attain fame and recognition also share similar ideas to prominent photographers? We expect that 
interviews with these photographers will reveal more detailed insights into their intent, self-identity and challenges than indirect retrospective analyses, which have dominated literature to date.

\section{Methodology}

Overall approach

To obtain both primary and second data, this study employed interviews, field research, and document analysis, with the former being the most important method. Brief explanations for each are provided below.

When conducting semi-structured interviews, photographers were requested beforehand to bring along several representative works as a basis for discussion. We applied a narrative studies approach described by Czarniawska (2004). Drawing on cues that arise during interview narratives, this approach mainly focuses on investigating the details of events or processes involving the participants rather than on the formal aspects of conversation between the researcher and the participants. In order to analyze the intentions of each photographer with regard to the contents of their representative photographs, we applied a hermeneutic approach that investigates the structural causes of particular events or statements (Wernet, 2014).

We also applied ethnographic techniques when collecting and analyzing data (Borneman \& Hammoudi, 2009; Sanjek, 1990) by visiting the places where the works of the surveyed photographers are actually presented to the public such as lectures or photo exhibitions. These first-hand field observations allowed the recording and analysis of the specific processes by which the nature photographers present and communicate their works.

This study draws on findings from an analysis of "non-technical literature" (Flick, 2014). Concretely, this documentation comprises of literature such as photographic books, textual and pictorial essays and articles written mainly by the photographers under scrutiny about the nature of their work. As Flick (2014) explains, non-technical literature can provide useful first-hand data for supporting and supplementing other forms of primary data like interview and observations. Since this research focuses on the findings from interviews or field surveys as a distinguishing characteristic relative to previous research, literature is mainly collected and examined to supplement interviews and direct participation observation. 


\section{Sampling strategies}

In Japanese, both traditional Chinese characters and katakana have been used to convey the term "nature photographer" (the latter allows direct adoption of the English pronunciation for the term) and describe photographers shooting natural world subjects. Takemura and Toyoda (1995) in their book History of Nature Photography in 50 Years: Nature Photo 1,500 Volumes deal exclusively with nature photography centered on animals and plants in Japan. The authors exclude landscape and astronomy photographs because of the different histories in these fields and the unique expertise required for nature photography dealing with animals and plants. Following this distinction, this study exclusively examines photographers who principally document animals and plants.

We opted for a theoretical sampling approach, gradually assembling the sample of nature photographers as our understanding of the phenomena emerged. As Glaser and Strauss (1967) explain, in theoretical sampling the sample is collected step-by-step and iteratively as the researcher decides which data should be collected next while collecting and coding the data and formulating the research questions. Our sample of 17 nature photographers (comprising 3 females and 14 males) is characterized by considerably different career durations, achievements, and visibility in the public sphere. As shown in Table 1, we use alphabet codes (e.g. A, B, C, etc.) when referring to each photographer in our findings so as to avoid emphasizing their individuality. Our sample includes four veteran photographers with extensive publishing experience dating back to the 1970s and 80s during which nature photography developed and was popularized. These veterans were chosen on the expectation they would be able to provide a representative perspective on the state of nature photography in Japan, expert knowledge, and an enriching discussion. In addition, we also examine newcomer photographers beginning professional activities only within the last decade in order to include a wider spectrum of fame and experience and provide a demographic balance to our sample.

The photographers examined in this study are principally practicing in Hokkaido prefecture in far northern Japan. Seven of the 17 photographers surveyed belong to the non-profit organization (NPO) “Association of Photographers in Hokkaido (North Finder)" who provided valuable assistance in introducing newcomers for our study. Hokkaido abounds in rich locations where photographers can capture nature in its undisturbed state. This is largely due to the relatively low population density of the region, 
its location in the climatic transition zone between temperate and subarctic regions (most other climates in Japan are temperate), and the fact that a large portion of wilderness remains untouched since the area was only settled by mainland Japanese approximately 150 years ago. Thus, as Hokkaido is blessed by a pristine nature mostly protected from human interference, images of its wilderness can be seen as representative of the unspoiled natural state of Japan's northern ecology.

\section{Data collection methods}

Interview research

Semi-structured interviews were conducted in person over the period January 2013 to May 2017. All interviews were fully recorded, transcribed, and analyzed as transcripts in accord with the research questions. After explaining the purpose and methods of this research, we asked the following questions based on the photographic works brought by the respondents for discussion:

1. What factors do you pay attention to when preparing for or shooting nature photographs?

2. What is the main intent of your work and what measures do you take to ensure this is accurately transmitted to the viewer?

3. What kind of activities you do engage in both as a nature photographer and outside of this profession?

4. What are some of the principle challenges faced by nature photographers today, and what are your opinions on these issues?

In addition, we also asked questions freely about their work, focusing on how they wanted to present their photographic images to the public, the various measures used for this, and challenges encountered in eliciting their intent through their photographs. In addition to having respondents explain the subject of the photograph, we also asked them to narrate their diverse thoughts on nature photography in general and what they had experienced during their field shooting experiences.

Interview times in most cases lasted approximately one hour although several respondents permitted more detailed discussions lasting from between two to five hours. In addition to eliciting narratives about the preparatory process, the longer interviews 
were able to explore elements seemingly not related directly to their photographic intentions such as the history of nature photography in Japan and general trends in the profession both in and outside Japan.

\section{Field research}

To further clarify how works from the surveyed photographers are presented to the public, where possible we visited public photographic exhibitions and audited lectures by the photographers concerned. We recorded and analyzed the contents of these lectures, particularly with regard to how the photographs were presented to the audience. Furthermore, during question and answer sessions or informal discussions afterwards we asked the photographers as much as possible about the intent and motivations behind their publication strategies.

\section{Document analysis}

Finally, to deepen our understanding about the 17 photographers examined, we collected and examined at least 64 documents including photographic essays, newspaper articles, and magazines_-some of which featured interviews with the photographers concerned. Findings from this document analysis were then compared to details obtained from interviews and field work, and served to re-enforce findings or provide new insights.

\section{Intent, tensions and contradictions in nature photography}

In what follows, findings concerning the intentions of nature photographers are organized mainly from three viewpoints: (1) efforts in acquiring natural scientific knowledge during the preparatory stage; (2) challenges and tensions encountered in constructing professional self-identities in relation to natural science, creative expression and the so-called cameraman profession; and (3) impacts and implications of stock photographs regarding the transmission of original intent.

Efforts to acquire knowledge from the natural sciences during the preparatory stage

Tackling our first research question, document analysis and interviews with photographers revealed that many devote much time and energy to acquiring knowledge from the natural sciences to build understanding into their subject. By comparing their first-hand observations of nature with scientific knowledge, literature demonstrates that 
veteran nature photographers will sometimes formulate hypothesis through their works (Mizukoshi, 2009). Historically, many of the pioneering, historical figures in nature photography in Japan would set up preparatory periods for their photographic shoots in the wild by visiting zoos, interviewing caregivers and examining archives of scientific knowledge on the animals targeted (Iwagou, 1989; Tanaka, 1970). Similarly, our interviews with younger photographers revealed they too are actively archiving and acquiring knowledge from natural scientific materials related to their subjects to deepen their understanding into biological and natural phenomena encountered during field observations. Photographer $F$ talks about his active assimilation of knowledge from natural science as follows:

I often tell newcomer photographers that they should obtain expert knowledge in this field so as to distinguish themselves from rivals. If photographers obtain such knowledge and are then able to show their originality through their work, they might attain expertise at an equal level to natural scientists. (Photographer F)

Nature photographers do not aim simply to reproduce scientific knowledge through their work. Instead, they also vigorously seek to contribute to new scientific knowledge themselves. For example, in the event that nature photographers find organisms or natural phenomena that cannot be confirmed by various forms of scientific literature, we learned that they actively communicate with researchers and academic societies specializing in natural science to build understanding into the subject concerned. For example, in recent years Photographer $D$ discovered a plant that had not been observed for almost a century and worked with a scientific researcher to ascertain the origins of this discovery. Concretely, this collaboration lead to the rediscovery of an endemic violet species blooming in the south of Hokkaido called Hidaka tatitsubo sumire that was listed in an encyclopedia from the early Showa era (1935). Although this plant had not been seen in that area for more than 70 years, the field work of Photographer $D$ led to the identification of plants mirroring the characteristics of historical book images. The rediscovery and survival of this species was confirmed for the first time in decades via this cooperation with taxonomists. The case thus indicates the tight integration between photographic image production and scientific knowledge that characterizes the work of many photographers and leads to the creation of scientifically credible images. 
When asking researchers to provide expert knowledge about particular subjects, we found that photographers are not simply requesting a one-way supply of knowledge from experts. Instead, they also seek to leverage working relationships with researchers to establish a two-way exchange and thus contribute to the pool of scientific knowledge. For example, when Photographer $P$ started working as a nature photographer, he observed a previously unknown behavior whereby bats are able to endure the snow of winters. He cooperated with a researcher specializing in bats at the Forest Research Institute and the two began to implement joint field studies in Sapporo and elsewhere in Hokkaido. This cooperative relationship led to the accumulation of discoveries of unusual overwintering behavior of this animal. In the words of Photographer F: “As a person documenting nature, I think that grasping and conveying as accurately as possible the scientific background (of the subject) is an important consideration to the people viewing my works.” Thus, as with earlier testimonies, this demonstrates a widely reported mindset that the acquisition of scientific literacy relating to photographic subjects constitutes a core intent for nature photographers. Similarly, this also suggests that communication with scientists and the realm of scientific knowledge also brings nature photographers to strive for objectivity and credibility from the perspective of natural science when capturing images of the natural world.

Findings also revealed that nature photographers investing efforts to acquire understanding from the natural sciences also undertake various actions in addition to taking pictures and exhibiting or publishing their images. As an example, several surveyed photographers have taken the initiative to participate in nature conservation efforts, acting as local interpreters, guides and specialist advisers (see Table 1). In addition, with some engaging in advocacy activities for the protection of local wildlife and ecosystems, most nature photographers are investing much time and effort to present themselves as specialists in local wildlife. It thus seems that nature photographers are well suited to these public outreach roles since their accumulation of natural science during the preparatory stage and interactions with scientists allows them to remain objective about the state of particular natural habitats from the viewpoint of science.

Challenges and tensions encountered in constructing professional self-identities

Moving on to our second research question, despite the active measures 
outlined above to acquire and contribute to natural scientific knowledge, in constructing their professional identities and pur- suing their intent, we also found that photographers are at the same time striving to maintain a cer- tain distance from natural science and other photographic fields. That is, while nature photographers work to develop their literacy in natural science related to their subjects, they also expressed some hesitancy and self-reflection that their role is not simply that of communicating scientific knowledge: "I don't believe it is necessary to pursue nature in a scientific and logical way" (Photographer J); “This is something I leave to the specialists” (Photographer Q). We even observed a desire to maintain a distance from natural science in a photographer who possesses a friendly relationship with an academic researcher: "Rendering visible the components of natural science are not a direct part of my job” (Photographer A). These findings suggest that for nature photographers, the pool of natural scientific knowledge is simply a reference point during the preparatory process for informing field observation and photography. That is, we did not observe an intent to solely and directly capture or express natural phenomena through the framing of current understanding documented in scientific research. As such, in the case where natural phenomena or ecology observed in the field are found to differ from scientific understanding, photographers tend to give greater priority to their first-hand field observations.

As evidence of this, when Photographer $O$ started his career, after reading that "Brown bears do not eat white skunk cabbage" in a famous and specialist scientific text, he went out to observe brown bear behavior directly in the field. During these observations, he discovered to the contrary that brown bears do in fact usually eat white skunk cabbage. Even examining literature to build understanding about subjects beforehand, this Photographer $O$ stated: "There is a part of me that feels that there is a big gap between books and the field.” However, “(t)he book is not to blame,” he continued, "The author who wrote the book just didn't happen to see a brown bear eating white skunk cabbage so the book is not lying to us.” As this anecdote reveals, mindful of potential situations when photographs taken in the field might not correspond with explanations from existing scientific resources, nature photographers are constantly cognizant of gaps between existing understanding and that gained through their own observations. So while nature photographers actively absorb scientific knowledge they do not explicitly set out to contribute new findings (like researchers). Rather, this is done indirectly, since the priority of their photograph shoots is first and foremost to record nature. Meanwhile, Shun 
Umezawa, whose career has focused on plant photography in Hokkaido for many years, does not regard himself as a photographer. Instead he views himself as a "visual encyclopedia craftsman" whose goal is to photograph the contents of his works in accord with knowledge from and the visual rigor demanded by natural science. An interview published by Ohashi (2003, p.34) elaborates on this conflict between being both a photographer and a visual encyclopedia craftsman:

People who are so-called "photographers" seek to express their own world through photographs. But in the case of work like mine, I have to strive to convey to people the reality of subjects as they actually are and ensure that my photographs are not influenced by my own subjectivity or personal feelings. But, well, to tell the truth, I also aspire to be a photographer or perhaps you could say that I still have the spirit of a creative. (...) Suppose for instance that when looking at a flower (in the field) I think to myself “Oh, this flower is so picturesque. How can I express this beauty?" But in the next instant I would snap back to the perspective of a visual encyclopedia craftsman and think "Hmm, if I shoot this flower from this angle I could better capture the stems and the characteristic of this species.”

The reason why Umezawa calls himself a visual encyclopedia craftsman in this way is because he chooses to suppress as much as possible the free expression of his ideas during shoots. Instead, for the sake of faithfully conveying the features of the subject-which are identified through field observations and continuous preparatory efforts to understand nature-he aims for photographs that seek to foster improved comprehension of the natural world.

These discussions point to a broader search for identity and raison-d'etre in the nature photographer community, also with respect to other professional circles of photographers. Incidentally, the term "photographer" in Japanese refers to those taking images as original work without any request from a company. On the other hand, for Japanese nature photographers the term “cameraman,” which is a Japanese expression made from Japanese English, refers to photographers primarily hired by advertising companies to go and shoot images in accord with precise instructions. Although both professions demand technical skills to take pictures, nature photographers think of their 
purpose as distinctly different from a cameraman. When emphasizing their key differences relative to cameraman, some nature photographers talk about themselves as "naturalists" and express dislike for the term cameraman or artist (Photographer E, F, K, $N)$. For these professionals, thinking about nature rather than photographs when in the field is a desirable attitude for a nature photographer. According to veteran Photographer $E$, the professions of a field worker and cameraman are distinct, as related below:

I think there is a way to distinguish between field photographers and cameraman. Cameraman who devote themselves to photographs like to wear a camera next their skin at all times and eagerly await any chance to click the shutter. But I prefer not to carry a camera except when shooting my work. This said, during field observations I always think about the final photographic image I am aiming for and this preparation helps me to achieve the type of images I wish to take. During this process, all of the scientific knowledge gathered until this point converges to produce various ideas or plans in my mind (...) In my view it would be hard to take good photographs without imagining the desired final image during field observations. (Photographer E)

The reason why Japanese nature photographers are critical against cameraman and artists is that they assume such photos are taken by people lacking natural scientific knowledge and who are mainly responding to shoot requests from advertising companies. At the same time, however, nature photographers are acutely aware of and pre-occupied by the fact that their intentions to incorporate knowledge from the natural sciences into their work might not be transmitted successfully to the viewer via photographic images alone. As an example, newcomer Photographer $N$ is continuously engaged in a trial-and-error process of exploring whether photographs can portray the intraspecific variations of the same species. During the interview, he related as follows his difficulties in conveying his intentions through his images:

Pictures are certainly convenient. But if you start thinking about species within intraspecific variations, there is no way that genetic elements and the essence of each species can be conveyed. It is my hope that somehow my photographic representations can sharpen these traits and bring them to the surface. But so far, I 
just end up supplementing photographs with words to convey these attributes. I sense this is the limit of the photograph. I guess this must be the realm of scholars. (Photographer $N$ )

Given the limitations of the photographic image, many photographers have taken initiatives such as holding explanatory talk shows or lectures in order to demonstrate more successfully to viewers their scientific understanding of subjects and explain in detail the characteristics of the living organisms and natural phenomena captured in their photographs. At such times, they incorporate knowledge from natural science to actively convey to the audience key points such as what the subject was doing and what was occurring in the surroundings at the time the photograph was taken. Yet since audiences are often more interested in cameras and photographic techniques than nature itself, during exhibitions photographers are frequently asked about their photographic methods in detail. However, as reflected by Photographer $P$ - "I would much prefer it that viewers would come up and ask me about why I took a particular photography instead of simply how I took it"-nature photographers would seemingly prefer to share with their audiences how their fieldwork and interactions with living creatures and natural phenomena has affected them rather than engaging in trivial conversations on photographic techniques (Photographers $F, L, M, N, O, P$ ).

As already explained earlier, nature photographers are driven by the intent to gain understanding into their subjects from an accumulation of field observations and acquisition of scientific knowledge and then convey this knowledge to viewers so that they might come to understand subjects like the photographer. And yet they are at the same time keenly aware that it is extremely hard to accomplish such an objective through pictures alone. This drives many to use elements other than photographs such as spoken or written words to convey their true intent. However, such countermeasures are not universally accepted. As one photographer critically remarked, "Ideally, I would rather take something that can be conveyed through the impact of a single photo, just like a famous photographer, if that were at all possible” (Photographer P). As can be seen, the challenge of how to accurately convey the true intentions behind photographs through images alone constitutes a core struggle and area of much exploration for nature photographers.

Although nature photographers are critical of cameraman-like and artistic 
shooting methods, they also demonstrate some degree of understanding about these ideas, sometimes even adopting these photographic styles into their own works and professional life. Photographer $F$ is an example of a photographer who sees the showcasing of knowledge from natural science related to his subjects as an indispensable part of his photographic exhibitions. Incidentally, this same Photographer $F$ is involved as a guide in nature observation sessions that do not specifically involve photography. When explaining subjects to participants, he consciously chooses photographs with high instructional value. Conversely, in photography classes with people who are highly interested in photography, he tends to showcase visually outstanding images with artistic appeal as teaching material so as to convey detailed information about the subjects to the audience. Thus although nature photographers are critical of cameraman and artistic shooting methods, in some cases they use artistic images in order to appeal to the public.

In parallel, many nature photographers also respect artistic expressions of nature that are not informed or bounded by natural science-which values accuracy of information over visual creativity. As key examples of nature photographers confessing their efforts to artistically express their ideas from natural scientific observation, veteran Photographer $B$ explained that his work compares the ecology of the fox against the lifestyle of humans; Photographer $O$ explained that he continuously seeks to photograph plant sprouts that look like a human face so as to "translate plant buds"; and Photographer $J$ endeavors to "pursue what it means to be human" through the form of forests and plants. As described above, the sense of distance that professional nature photographers seek to maintain from cameraman and artists is not one-sided, but rather, complex and multifaceted. The nature of this distance is the topic of much debate and personal struggle within the photographic community. As described in his autobiography by Iwagou Tokumitsu, who was active in the dawn of nature photography, nature photographs might arise from two motivations: (1) "faithfully pursuing the form and activities of subjects as closely as possible” and (2) "treating a subject as a material of self-expression and ignoring the ecological aspects to some extent” (Iwagou, 1989, p. 270). "In either way", he explains "I think it is impossible to determine the essence of nature photographs clearly and unequivocally.” Though Iwagou himself was a photographer who would only take images after a long-term and deliberate observation of nature, he stated expectations from the 1980s that the contribution of nature photographs - of which an increasing share appeared as artistic — would not be limited to advancing scientific knowledge, but equally, 
further the development of liberal interpretation and expressions.

As evidence combined from the document analysis and interviews demonstrates, nature photographers as a community are (1) actively seeking to maintain a certain distance from cameraman and artists and (2) grappling with competing desires to either express creativity based on their own observation or to faithfully represent subjects based on natural scientific knowledge (Umezawa, as the visual encyclopedia craftsman, usually chooses the latter). In addition, these findings also demonstrate that photographers are experiencing much difficulties in conveying to the public through images alone both these intentions and their understanding of nature that has come from direct observation and accumulation of natural scientific knowledge. This drives them to undertake additional communicative measures such as textual explanations or public lectures. Interviews with practicing photographers were the most helpful for understanding these issues, since such aspects are not typically conveyed in the words of documentation from veteran photographers.

\section{Implications of the stock photography industry on intent and professional identity}

Responding to our third research question, this section tackles the issue of stock photography. This emerged as a major area of concern for nature photographers with implications for the transmission of the original intent of photographers. This is because findings revealed that many publishers use nature photographs for the purpose of rousing public interest in nature conservation, typically without confirming the original intentions of the photographers concerned.

In one interview, Photographer $C$ described how he was once informed that his works were used for biodiversity pamphlets published by The Ministry of the Environment. This pamphlet entitled Images of the National Land in Japan in 100 Years portrays a future vision of the natural environment in the next 100 years. After firstly explaining that human activities in Japan have disrupted ecosystems over the past 100 years, the pamphlet then predicts a reversal of this situation as a complete restoration of ecosystems and sustainable management occurs over the next century. Works such as those from Photographer $C$ feature prominently in the same pages as these future forecasts. In other words, some of the nature photographs used in environmental policies in Japan have been treated as materials attached with politically meaning. Veteran Photographer $C$ talked about the process by which political meaning is attached to nature 
photographs as follows:

Publishers tend to search for images that can be used for environmental policies from stock photographs collections in photo libraries. They then publish their chosen images without confirming the intentions of the photographer. In such cases, the publishers then eventually inform the listing fee to the photographers afterwards. (Photographer C)

Though this same photographer did not strongly oppose to the diffusion of photographic images via stock photos used by government agencies and the attachment of political meaning during this process, he expressed dissatisfaction towards the current system, which masks the original intent of the photographer:

In Japan, there are many cases where nature photographs are treated as mere "visual materials"; that is, as stock photographs. Therefore, it would be unlikely that the original meaning of the photograph would be reflected precisely and systematically unless one has strong bonds with local politicians. (Photographer $C$ )

As this statement suggests, since nature photographs made available to publishers are often treated as stock photographs or source materials, nature photographers appear to be aware that their true intentions cannot be transmitted to viewers through such a system. Although they are not openly opposing this system, many appear to be dissatisfied with this means of diffusing images in exchange for monetary income. Aware of the inability to convey the true intent of the photographers through widely appropriated stock images alone, some such as veteran Photographer $D$ below emphasize the value of publishing works in photographic books or photo exhibitions so as to more fully convey intent:

Although many people are taking nature photographs profusely I don’t think their professionalism will bloom unless they exhibit their works in authoritative places. At least, I recommend that they publish their work in a reasonably authoritative place such as photo exhibition. I don't see how young people will be able to make a living just by uploading (stock photos) on the web. (Photographer D)

In addition to this view from veteran Photographer $D$, the belief that "publishing nature 
photographs to the public should occur via printed media” (Photographers L, O, Q) was widely expressed during interviews, particularly younger photographers. As creative individuals, they believe that stock photographs are unsuited to accurately conveying their original intentions, and they expressed dissatisfaction regarding the dominating stock photo process where their images are processed and digitally diffused via the Internet without any understanding about the intent of the person taking the picture. Incidentally, the widespread preference for paper medium such as exhibitions and photographic books over publishing via stock images observed in this study shows much parallel with a trend noted by Schwartz (2016) in a community of conservation photographers expressing much reluctance to rely on online technology when diffusing images.

As mentioned in the introduction, the Japan Photographers Association has regarded stock photographs favorably until around 2000. This positive appraisal is influenced by the successive discontinuation of natural science magazines as a result of diminishing sales from the 1990s due to the rise of digital media. During interviews, multiple photographers stated that natural science magazines once contributed greatly to the career development of newcomer nature photographers (Photographers $E, L, P$ ). Yet for the younger nature photographers arriving on the scene more recently, opportunities to publish in natural science magazines have decreased sharply. Consequently, stock photography agencies are today playing a large role in supporting the professional development of newcomers specialized in nature photography.

However, the stock photography market today is undergoing large structural changes, with smaller firms specialized in nature photographs disappearing due to takeovers by larger competitors, particularly since the 1990s (Photographers $A, D, L, N$ ), as consistent with the merger rise of Aflo, one of Japans' large stock photo industries in the 2000s (Stern, 2008). As a result of this dynamic, the market environment of smaller and specialized stock photography firms that were previously more suited to understanding and respecting the true intentions of photographers has rapidly decreased, particularly relative to the more prosperous print-dominated 1970s and 1980s. From another perspective, however, the growth of the Internet nowadays has allowed many amateur photographers to enter the market by publishing images freely on the Internet or earning income by contributing photographs to stock libraries. As veteran Photographer A elucidated, "I think that the rapid expansion of stock photo has given the preconception 
to both photographers and publishers that all possible photo subjects in nature have already been shot and uploaded." As a result, the stock photo paradigm has on the one hand created a market environment where the border between amateurs and professionals is becoming more and more obscure. On the other hand, however, it is possible that stock photos no longer provide a suited replacement of natural science magazines from the perspective of transmitting the intent of the photographer to the public. The implication of this situation is that before the domination of the stock photography industry, in the past the public were able to easily view nature photographs with a certain "quality assurance” from the perspective of the natural sciences. This was largely due to the editing of publishers and conscious selection of images from photographers, which took into account their original intentions. Nowadays, however, due to the propagation of the Internet these pictures with a scientific credibility are frequently mixed with unsorted pictures that are able to be posted by anybody with Internet access. Given this situation, would it be easy for readers and photographers to curate which nature photographs accurately depict the photo subjects based on natural science? Presumably, this conventional stock photograph system could not sufficiently offer qualified pictures that faithfully present natural world subjects in a manner consistent with the natural sciences.

\section{Conclusion}

To date, nature photographs have been widely used for brochures and advertisements related to environmental problems. But what exactly are the original intentions of the photographers, and what messages do they wish to convey through their photographs? Are their works used carefully so as not to contradict the photographer's intentions and the context within which the images were taken? This study has increased understanding into these areas-particularly the preparatory process leading up to the moment a subject is captured and, in addition, the motivations, objectives and sense of purpose that photographers attach to their work.

Using qualitative methods such as interviews and field work supplemented by document analysis, this study examined: (1) the kind of preparatory measures taken by nature photographers before shoots and the intent that drives their photographic work, (2) the manner by which they self-identity and attribute meaning to their role as nature photographers, and (3) challenges encountered in conveying their intent to the public 
through images, and countermeasures to overcome these.

Most nature photographers actively work to absorb scientific knowledge relevant to their subjects during the preparatory process. Such knowledge is sourced beforehand by examining an array of scientific literature, viewing books, and actively engaging with researchers from the natural sciences. Thus, a key intent for nature photographers is to convey to the public through images their personal discoveries and intimate understanding of nature. This is derived from a combination of first-hand field observations and the accumulation of existing natural scientific knowledge. Although generally they keep a certain distance from researchers, in some cases photographers seek their collaboration to clarify their new discoveries that do not correspond with current scientific knowledge. Furthermore, since they have acquired significant scientific understanding, many complement their professional role as a nature photographer by assuming expert educational roles for the public about local wildlife and flora.

Since the contents of nature photographs are based on specific and personal encounters with nature during field observations in combination with scientific knowledge, this intent is central to the self-identify of nature photographers. In parallel, this also sets their work apart from cameraman-like and artistic photographs. Yet in constructing their self-identity as nature photographers and attributing a sense of purpose to their work, we discovered that they are grappling with significant internal tensions and contradictions when deciding the optimal distance to place between their profession and that of cameraman and the realm of artistic expression.

Regarding the rise of stock images and the treatment of nature photos as commodities where the intent of photographers is routinely ignored, on the one hand this system appears to be masking and erasing the intent and therefore raison-d'etre of nature photographers. For viewers, on the other hand, widespread diffusion of photographic images through this system instead of via scientifically-oriented publication outlets might be robbing the occasion to obtain valuable knowledge about the natural world from scientifically literate specialists. If this situation continues, eventually, the public might encounter difficulties accessing photographs with a quality assurance derived from the scientific understanding that underpins their production and accurate presentation of the subject. As urbanization continues and more and more humans lose the occasion to learn about nature from first-hand experiences, our understanding of the natural world depends more and more on images. Thus, preserving the scientific accuracy of visual 
reproductions of the natural world while balancing visual integrity with artistic aspirations is surely an important way of ensuring the "truth" of nature is conveyed. Ensuring this would harbor benefits for both viewers and specialized nature photographers. As one potential way of overcoming this situation, stock photography agencies in the future could take the initiative of allowing nature photographers to convey their intentions during the image registration process. Attaching concrete texts describing their preparatory process would help sharing their faithful approach to the viewers.

As a key limitation, following the definition of nature photographers suggested by Takemura and Toyoda (1995), the scope of this research focused on those individuals taking pictures of animals and plants. We did not clarify whether our findings might also apply to photographs covering nature in general, such as landscape photography, mountain photography, astrophotography, and so on. Therefore, expanding the scope of this study to consider whether the findings might also apply to a wider community of socalled nature photographers, inclusive of these other sub-genres, would constitute an important topic for future research. In addition, comparative research with nature photographers around the world would also reveal how much our findings are limited to the context of Japan's current situation.

As other important considerations, this study focused on photographers who have continuously published their pictures via printed media. Following the impact of the digital media revolution such as websites and social media, the socio-economic landscape surrounding current Japanese nature photographers is changing dramatically-as the discontinuation of many paper-based publications shows. Thus, as another direction for further research it might also be important to examine those photographers making the transition to digital publishing platforms while also considering the other publishing players involved in the stock photograph industry.

\section{Acknowledgments}

In conducting this research, we are highly thankful to the cooperation of the environmental group "Eco-network" and NPO “Association of Photographers in Hokkaido (North Finder)" for introductions to numerous photographers. We also owe special gratitude to the photographers who cooperated for our long interviews. We also thank Prof. Taisuke Miyauchi at Hokkaido University Faculty of Letters for providing 
useful comments to this research over an extended period of time. We would also like to thank the reviewers who demonstrated much understanding about our research and provided concrete suggestions for improving this manuscript.

\section{References}

Banerjee, S. (2003). Arctic national wildlife refugee - seasons of life and land. Seattle: The Mountaineers Book.

Borneman, J., \& Hammoudi, A. (2009). Being there - The fieldwork encounter and the making of truth. Berkeley, CA:University of California Press.

Cox, R., \& Steve, S. (2015). The media/communication strategies of environmental pressure groups and NGOs. In A. Hansen \& R. Cox (Eds.), The Routledge Handbook of environment and communication (pp. 73-85). London: Routledge.

Czarniawska, B. (2004). Narratives in social science research. London: Sage.

Deluca, K., \& Demo, A. T. (2000). Imaging nature: Watkins, Yosemite, and the birth of environmentalism. Critical Studies in Mass Communication, 17(3), 241-260. doi:10.1080/15295030009388395

Deluca, M. K. (1997). Image politics: The new rhetoric of environmental activism. London: Routledge.

Doyle, J. (2007). Picturing the clima(c)tic: Greenpeace and the representational politics of climate change communication. Science as Culture, 16(2), 129-150. doi:10.1080/09505430701368938

Dunaway, F. (2005). Natural visions: The power of images in American environmental reform. Chicago: The University of Chicago Press.

Egan, T. (2003, May 3). Smithsonian is no safe for exhibit on Arctic Wildlife Refuge. The 
New York Times. Retrieved from http://www.nytimes.com/2003/05/02/us/smithsonian-isno-safe-haven-for-exhibit-on-arctic-wildlife-refuge. html.

Flick, U. (2014). An introduction to qualitative research 5th edition. London: Sage.

Foale, S., \& Martha, M. (2005). Green fantasies: Photographic representations of biodiversity and ecotourism in the western pacific. Journal of Political Ecology, 13(1), 1-22. doi: 10.2458/v12i1.21671

Gervais, E. A. (2016). Who has time for that?: Understanding media use among conservation photographers. International Journal of Communication, 10, 706-725.

Glaser, B. G., \& Strauss, A. L. (1967) The discovery of grounded theory: Strategies for qualitative research. Chicago, IL: Aldine.

Imahashi, E. (2008). Foto riterashi: Houdoushasin to yomu rinri [Photo literacy: Press photo and reading ethics]. Tokyo: Chuo Kouron Shinsha.

Iwagou, T. (1989). Doubutsu kamera man: doubutsu shashin no Showa [Animal photographer: Animal photo in Showa]. Tokyo: Asashi Shinbun Press.

Japan Professional Photographers Society. (2000). Nihon gendai shasin shi [The history of Japanese contemporary photography]. Tokyo: Heibonsha.

Ketchum, R., \& Carey, D. K. (1994). The Tongass: Alaska's vanishing rain forest. New York: Aperture.

Ministry of the Environment in Japan (2010). Nature conservation bureau (ed.). Inochi ha sasaeau (Species support each other); Biodiversity action plan 2010. Ministry of the Environment in Japan.

Mizukoshi, T. (2009). Watashi no yama no hakubutsu shi [My mountain's magazine]. Tokyo: Shinchosha. 
Nobuoka, A. (2009). Dai san shou: Toikakeru shizen: shasinka Hoshino Michio no Arasuka wo meguru taiwa 20 seiki nichibei kan ni okeru kankyou hyoushou no kousaku [Chapter 3: Nature questioning: photographer Michio Hoshino’s Alaska experience, dialogue on nature combination of environmental representation between the 20th century Japan and the United States]. (Doctoral dissertation). The University of Tokyo Comparative Culture.

O’Neil, S. J., \& Nicholas, S. (2014). Climate change and visual imagery. WIREs Climate Change, 5(1), 73-87. doi:10.1002/wcc.249

Ohashi, K. (2003). Shasinka tanbou dai 3 kai Umezawa Shun (Visiting photographer part3 Umezawa Shun). In Faura editorial department (ed.), Faura vol.4 Shima-aoji (Yellow-breasted bunting) (pp. 32-36). Sapporo: Naturally.

Pezzullo, P. C., \& Cox, R. (2018). Environmental communication and the public sphere 5th edition. London: Sage.

Sanjek, R. (1990). Fieldnotes: The making of anthropology. Albany: Sate University of New York Press.

Schwarz, E. A. G. (2013). Visualizing the Chesapeake Bay watershed debate. Environmental Communication, 7(2), 169-190. doi:10.1080/17524032.2013.781516

Seppannen, J., \& Esa, V. (2003). Visualizing biodiversity: The role of photographs in environmental discourse. Science as Culture, 12(1), 59-85. doi:10.1080/0950543032000062263

Sontag, S. translated by Kondo, K. (1979). Shashin-ron (On photography). Tokyo: Shobunsha.

Stern, J.D. (2008, May 2). Japan’s am-images merges with Aflo. Selling Stock. Retrieved from https://www.selling- stock.com/Article/japans-am-images-merges-with-aflo 
Takemura, Y., \& Toyoda, H. (1995). Sizen shasin 50 nenshi: Neicha foto 1500 satsu no ayumi [History of nature photography in 50 years: Nature photo 1,500 volumes]. Tokyo: Bunnichi Sougou Press.

Tanaka, K. (1970). Yasei doubutsu wo ou: So no zuisou teki satuei hou [The ideal photography method of chasing wild animals]. Tokyo: Geijutsu seikatsusha.

Tollmann, V. (2014) The uncanny polar bear: Activists visually attack an overly emotionalized image clone. In S. Birgit \& T. Nocke (Eds.), Image politics of climate change: Visualizations, imaginations, documentations (pp. 249-272). Bielefeld: Transcript Verlag.

Wernet, A. (2014). Hermeneutics and objective hermeneutics. In U. Flick (Ed.), The SAGE handbook of qualitative data analysis (pp. 234-246). London: Sage. 


\section{Appendix 1:}

\section{Table 1: List of respondents}

*Members belong to NPO “Association of Photographers in Hokkaido (North Finder)”

\begin{tabular}{ccrl}
\hline Code & Age & $\begin{array}{c}\text { Career } \\
\text { since }\end{array}$ & Other activities in addition to photography \\
\hline A & $70 s$ & 1964 & Lecturer in University \\
\hline B & $70 s$ & 1966 & Initiative in local environmental group \\
\hline C & $70 s$ & 1967 & Adviser of nature films
\end{tabular}

\begin{tabular}{cccl}
\hline$D^{*}$ & $60 s$ & 1972 & Participation in local environmental group \\
\hline E & $60 \mathrm{~s}$ & 1973 & Representative in bird conservation organization \\
\hline F $^{*}$ & $50 \mathrm{~s}$ & 1976 & Representative in local nature guide group \\
\hline G & $50 \mathrm{~s}$ & 1986 & N/A
\end{tabular}

\begin{tabular}{cccl}
\hline $\mathrm{H}^{*}$ & $50 \mathrm{~s}$ & 1993 & Member of environmental group \\
\hline $\mathrm{I}$ & $40 \mathrm{~s}$ & 1994 & N/A
\end{tabular}

\begin{tabular}{cccl}
\hline $\mathrm{J}$ & $40 \mathrm{~s}$ & 1996 & Lecturer in nature observation and tracking \\
\hline $\mathrm{K}^{*}$ & $40 \mathrm{~s}$ & 1997 & Lecturer in nature observation and tracking \\
\hline $\mathrm{L}$ & $50 \mathrm{~s}$ & 1999 & Member of bird conservation organization \\
\hline $\mathrm{M}^{*}$ & $40 \mathrm{~s}$ & 2000 & Adviser of nature films
\end{tabular}

\begin{tabular}{cccl}
\hline $\mathrm{N}$ & 40s & 2001 & Adviser in local forestry cooperatives \\
\hline O* & 40s & 2004 & $\begin{array}{l}\text { Lecturer in nature observation and tracking, Adviser of } \\
\text { nature films }\end{array}$ \\
\hline P & $30 s$ & 2007 & Lecturer in nature observation and tracking \\
\hline Q & $50 s$ & 2007 & Adviser of local environmental group \\
\hline
\end{tabular}

